\title{
Infeccão Natural de Jatobá por Phomopsis sp. no Distrito Federal
}

\author{
Maria José d’A. Charchar ${ }^{1}$, José R. N. Anjos ${ }^{1} \&$ José T. Melo $^{1}$ \\ ${ }^{1}$ Centro de Pesquisa Agropecuária dos Cerrados, Empresa Brasileira de Pesquisa Agropecuária, \\ Cx. Postal 08223, CEP 73 301-970, Planaltina-DF, e-mail:mdavila@cpac.embrapa.br
}

(Aceito para publicação em 20/11/2002)

Autor para correspondência: Maria José d’Avila Charchar

CHARCHAR, M.J.d’A., ANJOS, J.R.N. \& MELO, J.T. Infecção natural de jatobá por Phomopsis sp. no Distrito Federal. Fitopatologia Brasileira 28:316-318. 2003.

\begin{abstract}
RESUMO
No ano de 1999, no Distrito Federal, em plantas de jatobá (Hymenaea stigonocarpa) foram observados sintomas de lesões foliares de onde foi isolado o fungo Phomopsis sp. Em condições de casa de vegetação, foram inoculadas folhas com o fungo em dez plantas de jatobá e dez foram mantidas como controle. Os sintomas desenvolvidos nas plantas inoculadas com ferimento foram observados no sétimo dia após inoculação, de onde o fungo Phomopsis sp. foi reisolado. Nas plantas controle não foram

observados sintomas. Este é o primeiro relato de Phomopsis sp. em folhas de jatobá, no Brasil, em condições naturais. De 13 espécies vegetais testadas para patogenicidade com este isolado, seguindo-se a mesma metodologia de inoculação 12 foram suscetíveis e apenas o maracujá-azedo (Passiflora edulis f. flavicarpa) não apresentou sintomas.

Palavras-chaves adicionais: mancha foliar, patogenicidade, cerrado.

\section{ABSTRACT}

Natural infection of jatobá by Phomopsis sp. in Federal District

The fungus Phomopsis sp. was isolated consistently from samples exhibiting leaf symptoms on jatobá (Hymenaea stigonocarpa) in Federal District, Brazil, in 1999. In the greenhouse, ten plants were inoculated and ten were left untreated. Leaf symptoms on jatobá were observed after one week on

wounded inoculated leaves, and Phomopsis sp. was successfully reisolated from disease tissue. No symptoms were seen on control plants. This is the first report of Phomopsis sp. found on jatobá in Brazil, under natural field conditions. This isolate also was inoculated on leaves of 13 plant species and caused leaves symptoms in 12 those plant tested for pathogenicity. The isolate was not pathogenic to Passiflora edulis f. flavicarpa plants
\end{abstract}

O jatobá (Hymenaea stigonocarpa Mart.), família Leguminosae subfamília Caesalpinoideae, é uma espécie arbórea, de ocorrência comum nos biomas Cerrado e Cerradão (Almeida et al., 1998), podendo atingir até $10 \mathrm{~m}$ de altura (Rizzini, 1971). Produz madeira, de excelente qualidade, muito dura e resistente, com densidade de $0,90 \mathrm{~g} / \mathrm{cm}^{3}$, por isso é utilizada na construção civil e naval (Almeida et al., 1998). Seus frutos possuem elevado teor de fibra alimentar (Silva, 1997) e são utilizados na alimentação humana e animal. A resina produzida por essa espécie é utilizada na indústria e na área farmacêutica (Almeida et al., 1998). Além das utilidades mencionadas, o jatobá é comumente empregado na arborização urbana (Lorenzi, 47.1998; Almeida, 2001). A exemplo de outras espécies vegetais, ele é afetado por agentes causadores de doenças: a ferrugem, causada por Crossopsora hymenaeae Dianese, Buriticá \& Hennen sp. nov. sp. nov. (Dianese, et al., 1994), a mancha da folha causada por Erythrogloeum hymenaeae Petr. (Ferreira, et al., 1992) e a associação de Pestalotia subcuticularis Guba com folhas do jatobá (Arrhenius \& Langenheim, 1986). O fungo Phomopsis sp. tem sido encontrado associado a sementes de espécies comuns nos Cerrados, como baru (Dipteryx alata Vog.) e caroba
[Cybistax antisyphilitica (Mart.) Mart.] (Santos, 1996), e a mancha foliar em aroeira (Myracrodruon urundeuva Fr.All.) (Anjos et al., 2001).

O objetivo desse trabalho foi identificar o agente causal de um tipo de lesão foliar em jatobá, determinar sua patogenicidade, e avaliar a reação de outras espécies vegetais ao isolado em estudo.

Folhas de plantas pertencentes a uma população de jatobá, com aproximadamente dez anos, cultivada na área experimental da Embrapa Cerrados, Planaltina, DF, apresentando sintomas com lesões necróticas arredondadas e tamanho variável, de cor marrom claro com fina borda marrom escura (Figura 1A) foram colhidas no mês de junho de 1999. A incidência deste tipo de sintoma não se apresentava de modo uniforme naquela população de jatobá, sendo o mesmo observado quanto à distribuição do sintoma na planta. $\mathrm{O}$ isolamento do agente causal foi realizado seguindo metodologia proposta por Charchar \& dos Anjos (2000). O fungo Phomopsis sp. freqüentemente isolado dos tecidos infetados apresentou conídios hialinos, unicelulares e de dois tipos: $\alpha$ medindo 5,0$8,75 \times 2,5 \mu \mathrm{m}$, com forma predominante de elipsóide para ovóide, e $\beta$ medindo $15-27,5 \times 1,25 \mu \mathrm{m}$, filiforme, onde a maioria 
Infecção natural de jatobá por Phomopsis sp. no Distrito Federal

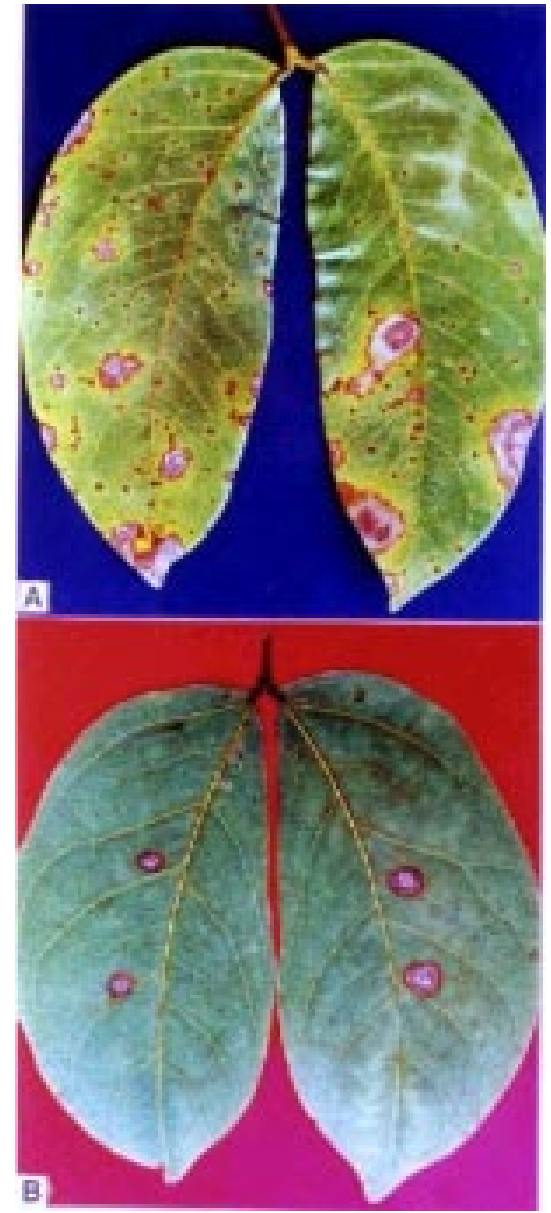

FIG. 1 - Folhas de jatobá (Hymenaea stigonocarpa) com sintomas causado por Phomopsis sp. A) Sintoma da infecção em condições de campo. B) Sintoma induzido por inoculação artificial do patógeno. apresentava curvatura em uma das extremidades. Uma cultura monospórica desse isolado foi enviada para o CABI Bioscience, em Egham, Surrey, Reino Unido, onde, a identificação do fungo Phomopsis sp. (IMI 382251) foi confirmada pelo Dr. P. F. Cannon. Para confirmação da patogenicidade procedeu-se a inoculação em duas folhas de dez mudas de jatobá, com quatro meses de idade em sacos plástico, em casa de vegetação. Na superfície de folhas feridas com estilete esterilizado e sem ferimento, foram transferidos discos com $5 \mathrm{~mm}$ de diâmetro retirados de culturas monospóricas do fungo desenvolvido durante dez dias em meio de BDA (batata-dextrose-agar), com abundante produção de conídios do tipo $\alpha$. No controle, dez plantas receberam o mesmo procedimento, usando-se apenas disco do meio de cultura sem o fungo. Após a inoculação, as plantas foram mantidas em câmara úmida, através da cobertura das mesmas com saco plástico, durante quatro dias em temperatura variável de 26-27 ${ }^{\circ} \mathrm{C}$. Os sintomas da doença foram observados em cerca de $90 \%$ das plantas de jatobá, no sétimo dia após a inoculação, nas folhas inoculadas sobre ferimento (Figura 1B). Phomopsis sp. foi reisolado dos tecidos infetados e comparado ao isolado original, completando-se assim os postulados de Koch. Nenhum sintoma foi observado nas testemunhas. O experimento foi repetido por duas vezes, obtendo-se o mesmo resultado.

Para verificar a reação de outras espécies vegetais, a Phomopsis sp. isolado do jatobá, 13 espécies pertencentes a dez famílias foram inoculadas com o mesmo isolado, seguindose metodologia idêntica à usada no teste de patogenicidade. Como pode ser observado (Tabela 1), o isolado de Phomopsis sp. em estudo mostrou-se capaz de infetar 12 das 13 espécies testadas. Apenas o maracujá-azedo (Passiflora edulis Sims f. flavicarpa Deg.) não foi hospedeira desse fungo.

TABELA 1 - Reação de espécies vegetais à doença quando inoculadas com Phomopsis sp. isolada do jatobá (Hymenaea stigonocarpa)

\begin{tabular}{|c|c|c|}
\hline Espécie testada & Família & $\begin{array}{c}\text { Plantas inoculadas com } \\
\text { sintomas }(\%)\end{array}$ \\
\hline Algodão (Gossypium hirsutum L. 'Deltapine') & Malvaceae & $73 \%$ \\
\hline Aroeira (Myracrodruon urundeuva Fr. All.) & Anacardiaceae & $95 \%$ \\
\hline Baru (Dipteryx alata Vog.) & Leguminosae (Papilionoideae) & $100 \%$ \\
\hline Café (Coffea arabica L. 'Acaiá Cerrado' & Rubiaceae & $80 \%$ \\
\hline Caju-do-campo (Anacardium humile Mart.) & Anacardiaceae & $100 \%$ \\
\hline Cagaita (Eugenia dysenterica Mart. ex. DC.) & Myrtaceae & $96 \%$ \\
\hline Estilosantes (Stylosanthes guianensis (Aub.) Sw. var. vulgaris Ferr.\& Costa 'Mineirão') & Leguminosae & $87 \%$ \\
\hline Gueroba ou guariroba (Syagrus oleracea Mart. Becc.) & Palmacea & $90 \%$ \\
\hline Mangaba (Hancornia speciosa Gomez) & Apocynaceae & $100 \%$ \\
\hline Maracujá-azedo (Passiflora edulis Sims f. flavicarpa Deg.) & Passifloraceae & $0 \%$ \\
\hline Pequi (Caryocar brasiliense Camb.) & Caryocaraceae & $82 \%$ \\
\hline Soja (Glycine max L. (Merr.) 'Carla') & Leguminosae & $96 \%$ \\
\hline Tomate (Lycopersicon esculentum Mill.) & Solanaceae & $89 \%$ \\
\hline
\end{tabular}

\section{REFERÊNCIAS BIBLIOGRÁFICAS}

ALMEIDA, S.P. de; PROENÇA, C.E.B.; SANO, S.M. \& RIBEIRO, J.F. Cerrado: Espécies vegetais úteis. Planaltina: EMBRAPA-CPAC. 1998.

ALMEIDA, S.P. de. Fruteiras nativas do Cerrado com potencial para arborização urbana, Brasília, DF. Resumos, IX Encontro nacional de arborização urbana. Brasília, 2001. Livro de Resumos. 2001. p.18.

ANJOS, J.R.N. dos, CHARCHAR, M.J. d’A. \& GUIMARÃES, D.P. Ocorrência de queima das folhas causada por Phomopsis sp. em aroeira no Distrito Federal. Fitopatologia Brasileira 26:649-650. 2001. ARRHENIUS, S.P. \& LANGENHEIM, J.H. The association of 


\section{M.J. Charchar et al.}

Pestalotia species with members of the leguminous tree genera Hymenaea and Copaifera in the neotropics. Mycologia 78:673-676. 1986.

CHARCHAR, M.J. d'A. \& ANJOS, J.R.N. dos. Phomopsis sp. em jatobá (Hymenaea stigonocarpa Mart). Anais, $51^{\circ}$ Congresso Nacional de Botânica. Brasília. 2000. p.72.

DIANESE, J.C.; BURITICÁ, P. \& HENNEN, J.F. The rust of "Jatobá": a new Crossopsora species from Neotropoca on Hymenaea (Leguminoseae). Fitopatologia Brasileira 19:588-591. 1994.

FERREIRA, F.A., DEMUNER, N.L. \& REZENDE, D.V. Mancha de folha, desfolha e antracnose do Jatobá (Hymenaea spp.) causadas por Erythrogloeum hymenaeae. Fitopatologia Brasileira 17:106-109. 1992.
LORENZI, H. Árvores Brasileiras. Manual de identificação e cultivo de plantas arbóreas nativas do Brasil. São Paulo, Ed. Plantarum, v. 1, 1998.

RIZZINI, C.T. Plantas do Brasil: árvores e madeiras úteis do Brasil. Manual de dendrologia brasileira. São Paulo: Edgard Blucher. 1971.

SANTOS, M.F. Análise da micoflora associada ao baru (Dipteryx alata Vog.) e a caroba (Cybistax antisyphilitica (Mart.) Mart.). (Tese de Mestrado). UnB Brasília, DF. 1996

SILVA, M.R. Caracterização química e nutricional da farinha de jatobá (Hymenaea stigonocarpa Mart.): desenvolvimento e otimização de produtos através de testes sensoriais afetivos. (Tese de Doutorado). UNICAMP. Campinas, SP. 1997. 